\title{
Evaluation of a Reinforced Concrete Wall Macroscopic Model for Coupled Nonlinear Shear-Flexure Interaction Response
}

\author{
Purnomo, J. ${ }^{*}$ and Chandra, J. ${ }^{1}$
}

\begin{abstract}
Reinforced concrete shear wall ( $\mathrm{RC}$ wall) is an important element in tall buildings, which provides strength and stiffness against lateral loadings, e.g. earthquake and wind. Numerous researches have been conducted to study its nonlinear behavior via microscopic and macroscopic model. The later approach is currently being widely explored since it has many advantages compared to the preceding models. A well-known macroscopic model, namely ShearFlexure-Interaction Multiple-Vertical-Line-Elements-Model (SFI-MVLEM) in the open source platform Open Sees, is capable of simulating the coupled nonlinear shear-flexure interaction response in the $\mathrm{RC}$ wall. This paper presents an evaluation to the applicability of SFI-MVLEM model to predict the coupled nonlinear shear-flexure behavior of $\mathrm{RC}$ wall specimens compared to experimental results in available literature. The analysis results show that the model is able to predict the behavior of $\mathrm{RC}$ wall considerably accurate in terms of hysteretic curves, cracking patterns, and contributions of shear and flexural displacement to total displacement.
\end{abstract}

Keywords: Shear-flexure interaction (SFI); reinforced concrete shear wall (RC wall); macroscopic model.

\section{Introduction}

Reinforced concrete shear wall ( $\mathrm{RC}$ wall) is an important element in seismic-resistant reinforced concrete buildings, which provides strength and stiffness against lateral loadings, e.g. earthquake and wind. Thus, numerous researches have been conducted to study the nonlinear behavior of $\mathrm{RC}$ wall under cyclic loading. $\mathrm{RC}$ wall is generally classified into three main categories, i.e. squat, moderate, and slender walls for those having aspect ratio (height to length ratio) of $0.35-1.50,1.50-2.50$, and greater than 2.50 , respectively. Squat RC wall tends to exhibit shear-controlled failure mechanism. On the other hand, slender RC wall exhibits flexure-controlled failure mechanism. Meanwhile, for moderate aspect ratio of $\mathrm{RC}$ wall, shear and flexural yielding usually occur at nearly the same period. This phenomenon is further commonly referred as shear-flexure interaction (SFI) [1].

It is worth noting that commonly built $\mathrm{RC}$ wall in the present constructions can be categorized as moderate to slender $\mathrm{RC}$ walls, which makes a comprehensive study of the coupled nonlinear shearflexure behavior of $\mathrm{RC}$ wall under cyclic loading is essential.

\footnotetext{
${ }^{1}$ Civil Engineering Department, Faculty of Civil Engineering and Planning, Petra Christian University, Jl. Siwalankerto 121-131, Surabaya 60236, INDONESIA

* Corresponding author: jpurnomo@petra.ac.id
}

Note: Discussion is expected before June, $1^{\text {st }} 2018$, and will be published in the "Civil Engineering Dimension", volume 20, number 2, September 2018.

Received 19 February 2018; revised 22 March 2018; accepted 28 March 2018.
This can be achieved via microscopic model by means of finite element based approach, which is able to provide remarkably accurate and comprehensive results. Nevertheless, this method requires enormous computational resources. On the other hand, macroscopic model offers considerably accurate results with less computational resources, thus makes this model preferable amongst researchers in recent years [2].

A fiber-panel based element as macroscopic model has been largely developed to model the nonlinear responses of $\mathrm{RC}$ wall. The most renowned model, acknowledged for its accuracy and stability of analysis, was the multiple vertical line element model (MVLEM), which was proposed by Orakcal et al. [3]. This model was further developed to incorporate the coupled behavior of shear-flexure response, and thus led to a new model known as shear-flexure interaction multiple vertical line elements model (SFI-MVLEM) [1]. This element has been extensively used to study the SFI behavior of rectangular $\mathrm{RC}$ walls with aspect ratio of 1.50 and 2.00 [1]. Nevertheless, the applicability of the element to simulate the SFI behavior of flanged and barbellshaped RC walls has not been observed thoroughly. Therefore, it is essential to investigate the reliability of this element to predict the coupled nonlinear SFI behavior of those types of $\mathrm{RC}$ walls.

This research aims to investigate the reliability of the SFI-MVLEM element to simulate nonlinear coupled SFI behavior of various types of RC walls, i.e. rectangular, flanged, and barbell, under lateral cyclic loading. The evaluation is done by comparing 
the hysteretic curves and cracking patterns resulted from the model to the results from experimental tests of RC walls. Further indicative aspect, i.e. the contribution of shear and flexural displacement to the total displacement is also considered. The whole results are finally summed up to justify the reliability of the model on simulating the SFI behavior of $\mathrm{RC}$ walls.

\section{SFI-MVLEM Model}

SFI-MVLEM model was developed from the previously existed macroscopic model, i.e. MVLEM proposed by Orakcal et al. [3], which treated shear and flexural responses separately. Further, Massone et al. [4] proposed MVLEM model for simulating behavior of coupled nonlinear SFI of RC walls under monotonic responses. The following research conducted revealed that the model was simple to formulate, numerically stable, efficient and reasonably accurate to predict flexural response of $\mathrm{RC}$ walls [5]. In 2010, Ulugtekin [6] proposed RC panel model incorporating the fixed strut angle model (FSAM), which was further extended by Orakcal et al. [7] to include the effect of aggregate shear interlock $\left(n_{u}\right)$. Finally in 2013, Kolozvari [1] modeled RC walls by replacing the uniaxial element of MVLEM by m-number of RC panels, which was henceforth known as SFI-MVLEM, and also added the effect of dowel action (a) to the model. The analytical model of the element is presented in Figure 1. Each SFI-MVLEM element was presented with six degree of freedoms (DOFs), which was located at the top and bottom rigid beams. These DOFs was introduced to capture normal strain in vertical direction $\left(\varepsilon_{y, i}\right)$ and shear strain $\left(\gamma_{x y, j}\right)$. Meanwhile, normal strain in horizontal direction was evaluated by introducing a total of m-number additional DOFs, which was added on each RC panel. Thus, each SFI-MVLEM element has overall $6+\mathrm{m}$ DOFs. Furthermore, ch indicates the center of relative rotation between the two rigid beams at top and bottom of the SFI-MVLEM element. A value $c=$ 0.4 was recommended by Vulcano et al. [8], and thus will be adopted in this paper.

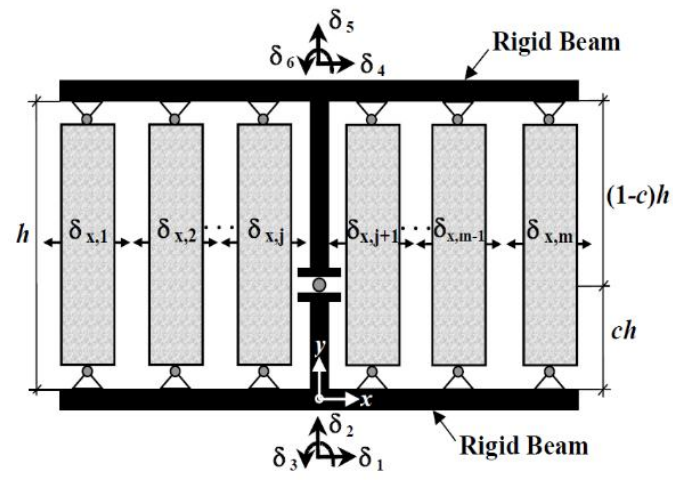

Figure 1. SFI-MVLEM Element [1]

\section{Constitutive Material}

A steel constitutive model proposed by Menegotto and Pinto [9], which was further expanded by Filippou et al. [10] to incorporate the effects of isotropic strain hardening, was used in the SFIMVLEM. The constitutive model relates the modulus of elasticity in elastic region (initial modulus) and in plastic region (yield modulus) by introducing ratio $b$, which is the ratio between the yield modulus to the initial modulus. The curved transition in the vicinity of intersection between the gradient of modulus of elasticity described the Bauschinger effects [1]. This model was selected due to its relatively simple formulation yet ability to perform isotropic strain hardening under compression and tension loading [5]. Meanwhile, for concrete, a constitutive material proposed by Chang and Mander [11] was used. The constitutive model was selected due to its flexibility to represent complex hysteretic behavior of confined and unconfined conditions of ordinary and high-strength concrete under cyclic loading. The model was also capable of capturing important features in concrete, such as compression and tension cyclic responses, stiffness degradation, and crack closure effects [5].

\section{Methods}

A well-known open source platform, i.e. Open Sees, was used to perform the analysis. The program requires problem definitions, which inputs may be divided into three main stages. Firstly to be defined were geometrical data of RC wall involving overall height, web thickness, as well as boundary elements. Thereafter was to specify the ratio of vertical, horizontal, and confining steel reinforcement ratio embedded in the wall. The last step was to define all necessary constitutive material parameters for concrete as well as steel, i.e. ultimate compressive stress $\left(f_{c}\right)$, modulus of elasticity $\left(\mathrm{E}_{\mathrm{c}}\right)$, and ultimate strain $\left(\varepsilon_{c}\right)$ for concrete and yield stress $\left(f_{y}\right)$, modulus of elasticity $\left(\mathrm{E}_{\mathrm{s}}\right)$, and strain hardening ratio $(\mathrm{b})$ for steel. Numerous constitutive models for concrete and steel are readily available in Open Sees. In this paper, Concrete $C M$, which was derived based on the model proposed by Chang and Mander [11], was chosen to represent the behavior of concrete. Meanwhile, a steel constitutive model Steel MPF proposed by Menegotto and Pinto [9] and further enhanced by Filippou et al. [10] was used to represent the behavior of steel.

The ability of SFI-MVLEM model in simulating the SFI behavior of rectangular RC walls presented in the previous research [1] needs to be confirmed before investigating other types of $\mathrm{RC}$ walls. The evaluation was done by comparing hysteretic curves 
obtained from Open Sees (hereafter model) to previously conducted experimental test results. The hysteretic curves were compared to observe the behavioral similarity. After the behavior of rectangular $\mathrm{RC}$ walls had been validated, the investigation was extended to simulate other shapes of $\mathrm{RC}$ walls, i.e. flanged and barbell. Additionally, cracking pattern of the model was extracted from Open Sees to be compared to the tested specimens. The specimens used to validate the results of rectangular $\mathrm{RC}$ walls were taken from specimen SW4 [12], SW21 and SW25 [13], and J4 [14]. Furthermore, models for flanged RC walls were taken from specimen J7 [14], and F1 [15]. The last, for the barbell-shaped RC walls, the specimens were taken from specimen M05C [16], B5 [15], LW2 [17], B3 [18], and W1 [19]. Each specimen was loaded by controlling the ultimate displacement.

\section{Results and Discussions}

The analysis of various shapes of $\mathrm{RC}$ walls was done via OpenSees. The main results of the analysis were the hysteretic curves, cracking patterns, and displacement profiles.

\section{Hysteretic Curves}

\section{Rectangular RC Wall Specimens}

Validation to SFI behavior of rectangular RC walls is represented by three specimens, i.e. SW4 [12], SW21 and SW25 [13]. First and foremost, Figure 2 shows the comparison of hysteretic curves of specimen SW4. The finding shows that the model predicts the ultimate load and displacement at $103.04 \mathrm{kN}$ and $21.85 \mathrm{~mm}$, respectively. In comparison, by visually graph estimation, the ultimate load and displacement of the experimental test was circa $103.88 \mathrm{kN}$ and $22.19 \mathrm{~mm}$. The results from the model inflict only slightly underestimation compared to the test, which is only $0.81 \%$ for ultimate load and $1.53 \%$ for displacement. However, judging from overall visual appearance of the hysteretic curve, the model's curve is slightly slimmer compared to the test.

Figure 3a shows the comparison of hysteretic curves for specimen SW21 [13] subjected to monotonic loading. In this case the model was loaded until the ultimate displacement obtained from experimental test, which was $11.40 \mathrm{~mm}$. The initial stiffness of the specimen is predicted higher by the model. Furthermore, the ultimate load predicted by the model is lower by $8.42 \%$. Although the model was loaded by limiting the ultimate displacement, one can continue the analysis to obtain the entire response of the model.

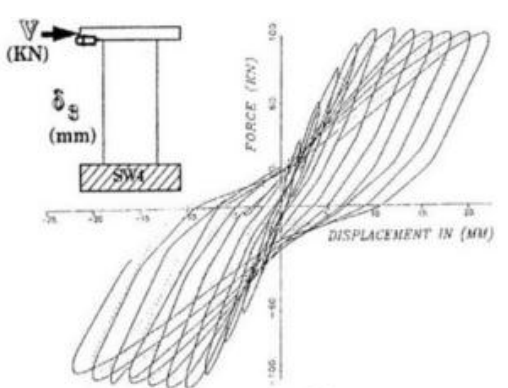

(a)

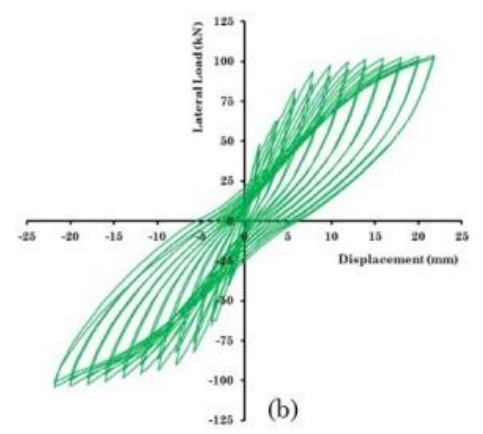

Figure 2. Comparison of Hysteretic Curves of Specimen SW4 [12] (a) Test (b) Model

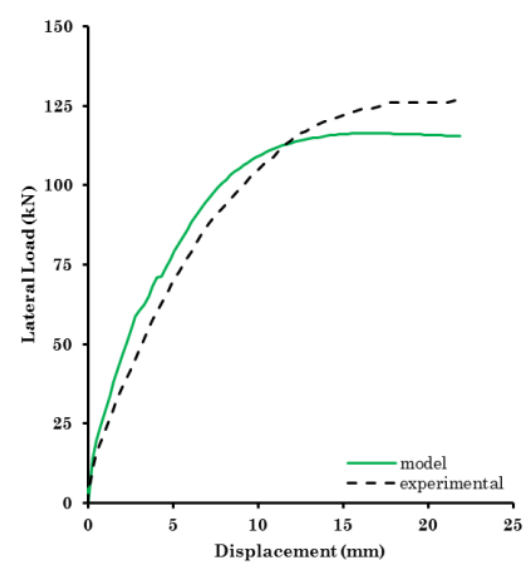

(a)

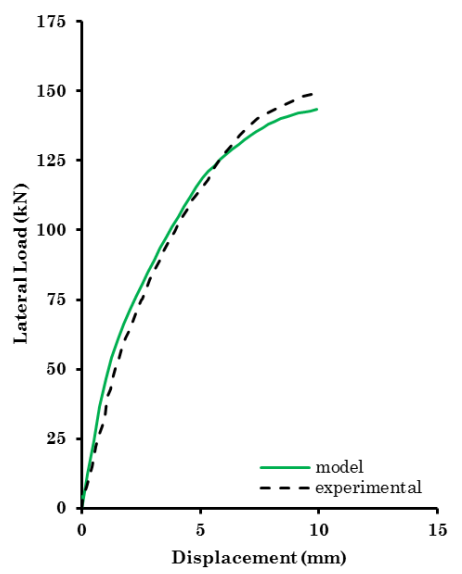

(b)

Figure 3. Comparison of Monotonic Curve of Specimens (a) SW21 [13] (b) SW25 [13] 
Another evaluation of $\mathrm{RC}$ wall behavior under monotonic loading is represented by specimen SW25 [13], which can be observed in Figure 3b. Identical to model for specimen SW21, model for this specimen was also modeled by limiting the ultimate displacement as obtained in the experimental result. It can be seen that the model is able to approximate the response of the specimen. However, there is underestimation of ultimate load by circa $3.86 \%$ when compared to the ultimate load of the experimental test, which was $149 \mathrm{kN}$. From these results and previous research results [1], it can be concluded that the SFI-MVLEM element can simulate quite well the behavior of rectangular RC walls under monotonic and cyclic lateral loadings.

\section{Flanged RC Wall Specimens}

The experimental test results of two flanged $\mathrm{RC}$ wall specimens, namely J7 [14] and F1 [15], were used to validate the output of the model. Firstly, Figure 4 shows the comparison of hysteretic curve of specimen J7 [14]. The ultimate loads predicted by the model were $843.70 \mathrm{kN}$ in the positive direction and $869.65 \mathrm{kN}$ in the negative direction. Although the wall had symmetrical cross section, the ultimate load predicted by the model introduced notable difference. This phenomenon is also verified by the result from the experimental test, which were $894.50 \mathrm{kN}$ and $827.30 \mathrm{kN}$ for positive and negative direction, respectively. The values indicate that the average discrepancy is circa $5 \%$. As for the ultimate drift, the model reaches $1 \%$ for both directions. This value shows $16 \%$ and $18 \%$ underestimation to ultimate drifts of experimental test in the positive and negative directions, which were $1.19 \%$ and $1.22 \%$. It is also notable that the model predicts stiffer hysteretic curve at the initial and final loading step. The overestimation of overall stiffness might be attributed to the application of the axial loading, which was applied to the middle of the SFI-MVLEM element and might have caused unevenly loading distribution along wall cross section. Furthermore, the model is also unable to capture the strength degradation of the $\mathrm{RC}$ wall beyond $1.00 \%$ drift.

The second specimen for flanged RC wall is F1 [15], which comparison of hysteretic curves is presented in Figure 5. It can be observed that the model overestimates the initial stiffness of the $\mathrm{RC}$ wall. Comparing the ultimate load in the positive direction, the model predicts lower value by $1.63 \%$. Moreover, slight underestimation also occurs in terms of ultimate deflection, which is circa $2.21 \%$. On the other hand, although there is negligible $0.97 \%$ overpredicted ultimate load in the negative direction, there is large difference in ultimate deflection. This is because the local failure mechanism occurred in the specimen, i.e. bar buckling of the web reinforcement, cannot be incorporated in the model.

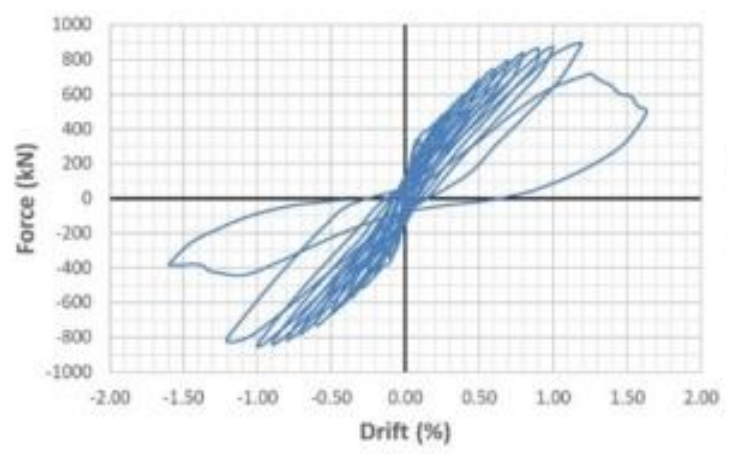

(a)

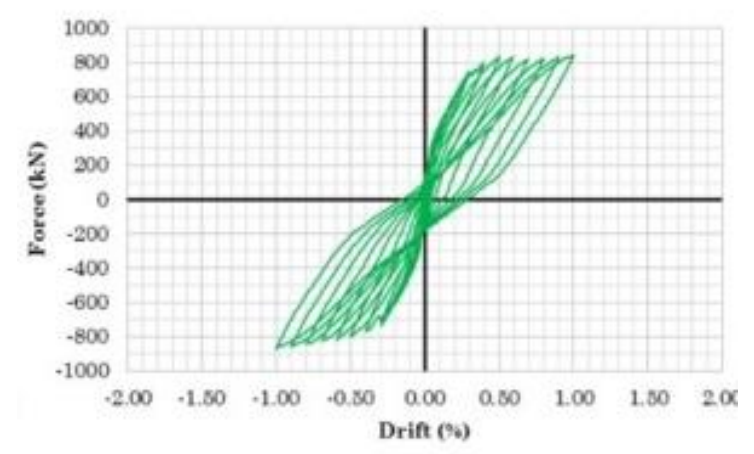

(b)

Figure 4. Comparison of Hysteretic Curves of Specimen J7 [14] (a) Test (b) Model
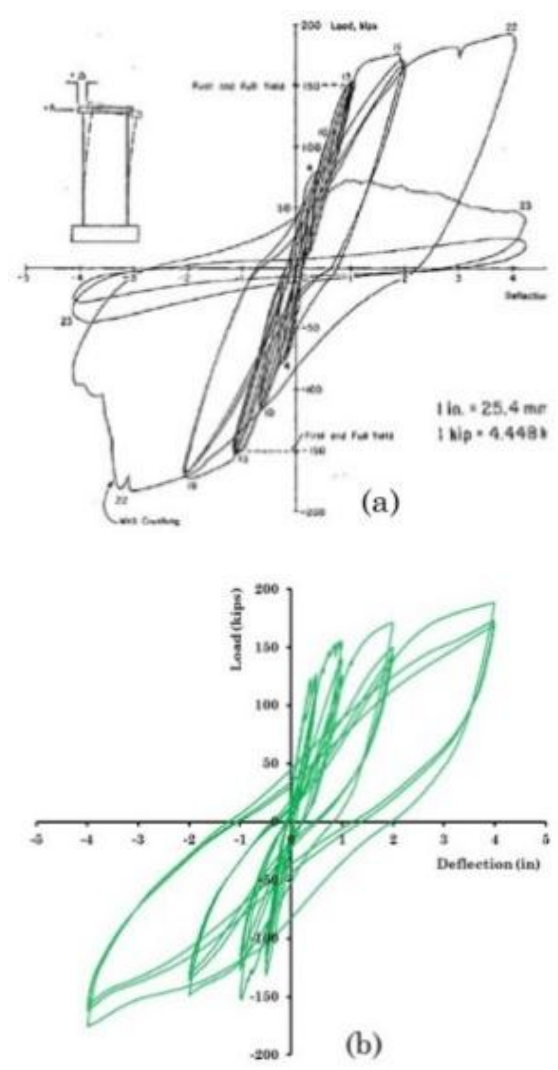

Figure 5. Comparison of Hysteretic Curves of Specimen F1 [15] (a) Test (b) Model 


\section{Barbell-shaped RC Walls}

The analysis of hysteretic curves of barbell-shaped $\mathrm{RC}$ walls is represented by specimen M05C [16], B5 [15], LW2 [17], and B3 [18]. Firstly, Figure 6 shows the comparison of hysteretic curves of specimen M05C [16]. Visually, it can be observed that the model slightly overestimated the response of the specimen. In the negative direction of applied load, the model predicts $3.39 \%$ higher displacement as well as $14.76 \%$ higher ultimate load. In accordance to that, the ultimate load in the positive direction is overestimated around $4.00 \%$. In contrast, the ultimate displacement in the positive direction is predicted $11.77 \%$ lower to the experimental results. This contradiction is in fact due to the specimen was in the verge of sudden failure, which might not be simulated by the model. Furthermore, the model shows higher initial stiffness compared to the test specimen.

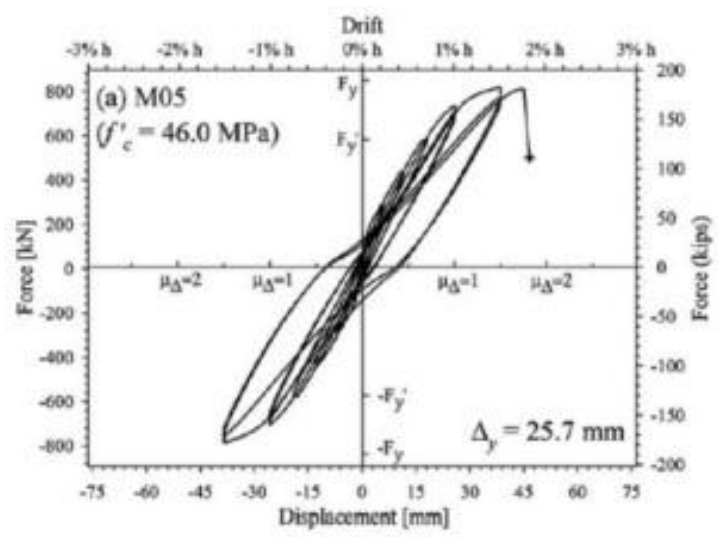

(a)

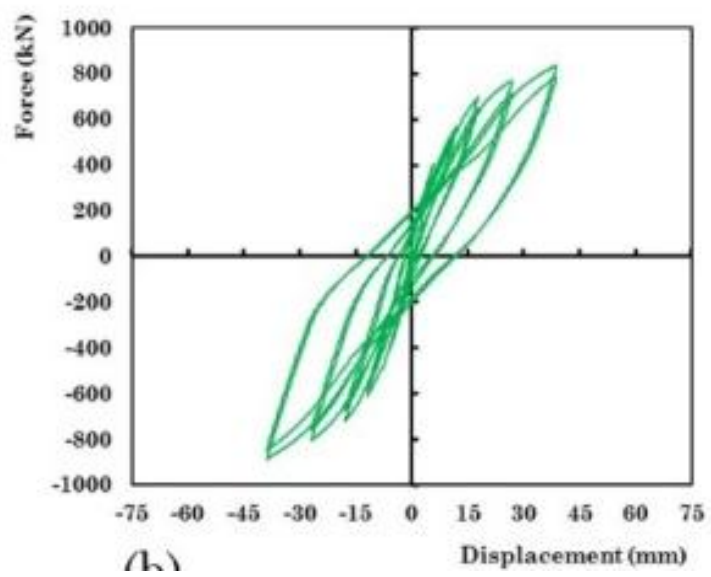

(b)

Figure 6. Comparison of Hysteretic Curves of Specimen M05C [16] (a) Test (b) Model

Secondly, Figure 7 shows the comparison of hysteretic curves of specimen B5 [15]. Similar to previous results, the model predicts higher initial stiffness and underestimates the stiffness at final load step.
The deflection obtained by the model is slightly overestimated, i.e. circa $0.41 \%$ and $1.83 \%$ in the positive and negative directions, respectively. In contrast, the ultimate loads in both directions are predicted lower compared to the test, which were around $12.25 \%$ and $19.86 \%$ for positive and negative directions, respectively. Nevertheless, judging from its shape, the model can predict quite well the hysteretic behavior of the specimen.
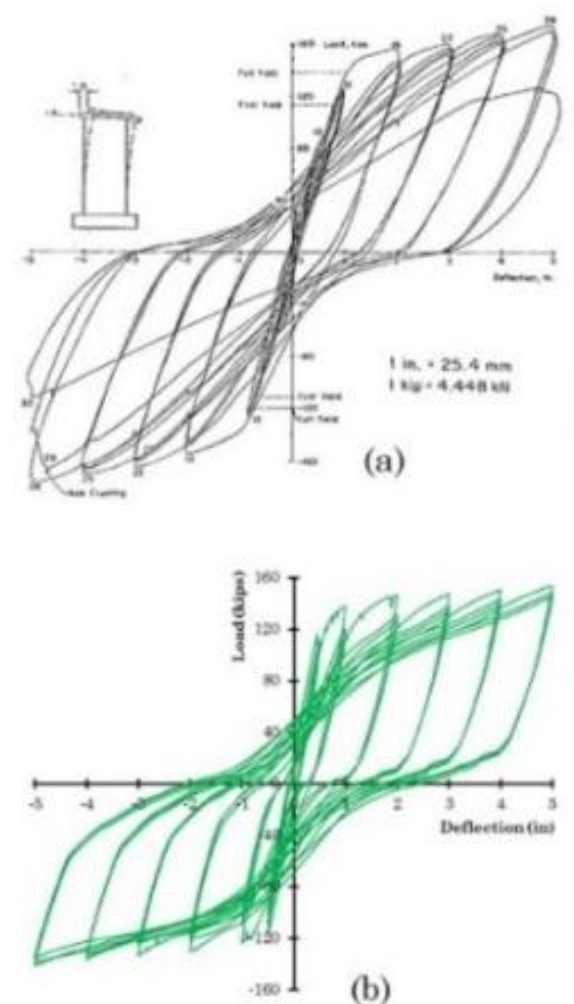

Figure 7. Comparison of Hysteretic Curves of Specimen B5 [15] (a) Test (b) Model

Thirdly, Figure 8 shows the comparison of hysteretic curves of specimen LW2 [17]. It can be observed that the model also predicts higher initial stiffness. Nonetheless, the overall stiffness of the wall is finely approximated. Another underestimation is also obtained in terms of ultimate load, which is $9.44 \%$ and $14.45 \%$ in the negative and positive directions, respectively. Moreover, it is clearly shown that the model overestimates the ultimate displacement in both directions of loading, which are $47.96 \%$ and $12.56 \%$ in negative and positive directions, respectively. This is because the model did not simulate well the local failure due to concrete crushing at the bottom of boundary element at the last loading cycle in the positive direction, and thus the hysteretic curve could proceed further for the negative direction. On the other hand, from the test results, it is shown that after the concrete crushing, the strength of RC wall was degraded and the test was not continued further into the negative direction. 


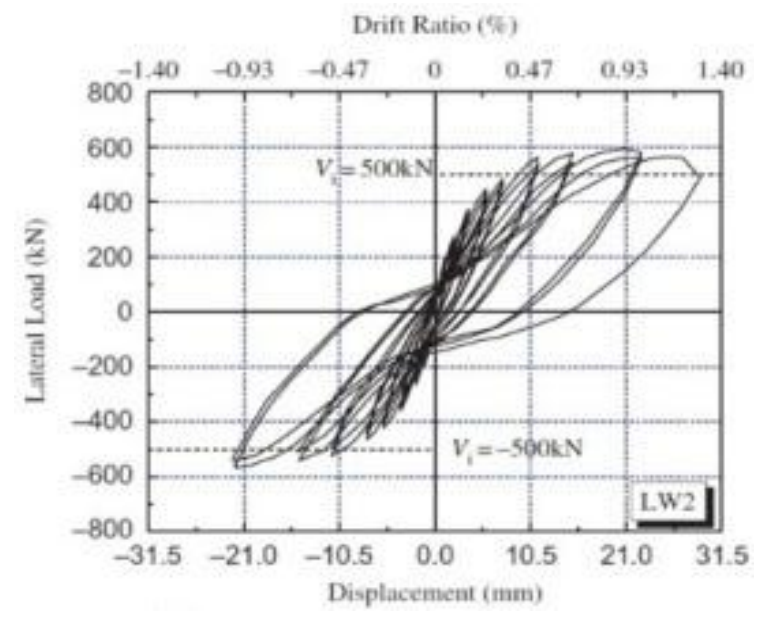

(a)

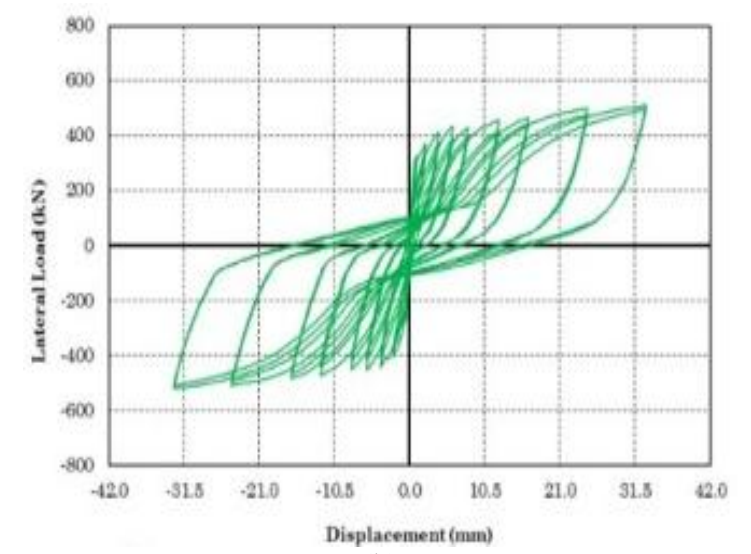

(b)

Figure 8. Comparison of Hysteretic Curves of Specimen LW2 [17] (a) Test (b) Model

Lastly, Figure 9 shows the comparison of hysteretic curves for specimen B3 [18]. The curve shows that the model is able to provide considerably accurate result. This is indicated by slight underestimation of ultimate displacement, which is $1.24 \%$ and $0.87 \%$ in negative and positive directions, respectively. Underestimation of ultimate load is also obtained, which is circa $2.69 \%$ in the negative direction. Meanwhile, the model predicts higher ultimate load around $1.59 \%$ in the positive direction. Judging from the numbers, it can be concluded that the model is able to simulate the behavior of the specimen in terms of ultimate load and displacement. It is also notable that the curve provided by the model has less pinching effect, which is mainly caused by the specified shear resistance factors.

\section{Cracking Patterns}

In this paper, cracking patterns are presented only for rectangular and barbell-shaped RC wall specimens. Rectangular RC walls are represented by specimen SW4 [12] and J4 [14] while barbell-shaped $\mathrm{RC}$ walls are represented by specimen B5 [15] and W1 [19].

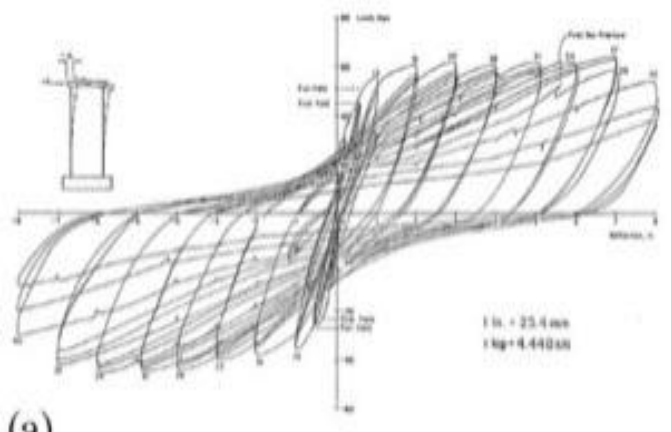

(a)

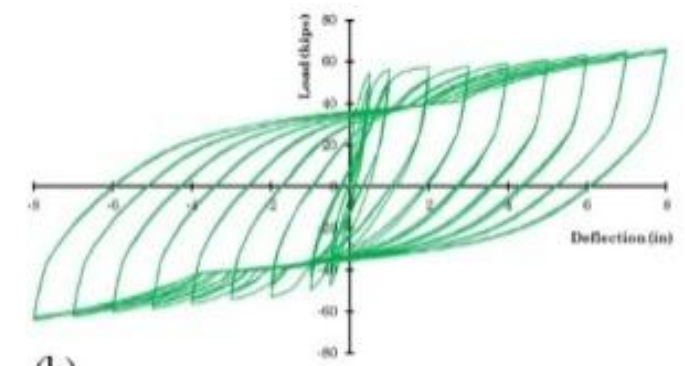

(b)

Figure 9. Comparison of Hysteretic Curves of Specimen B3 [18] (a) Test (b) Model

\section{Rectangular RC Walls Specimens}

Figure 10 shows the comparison of cracking patterns for specimen SW4 [12]. It can be seen that the cracking angles resulted from the model at the boundary elements are similar to those of experimental results except at the bottom of the wall. The model is also able to show gradual changes in cracking angle along the boundary elements. Besides, the cracking patterns at the wall web resulted from the model are also similar with those of experimental results, except at the bottom of the wall. The cracking angle in the vicinity is accurate only for one direction whilst predicts less in the other direction. This may be attributed to the adoption of FSAM theory in the model.

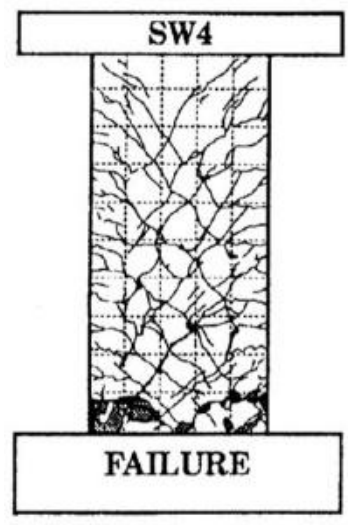

(a)

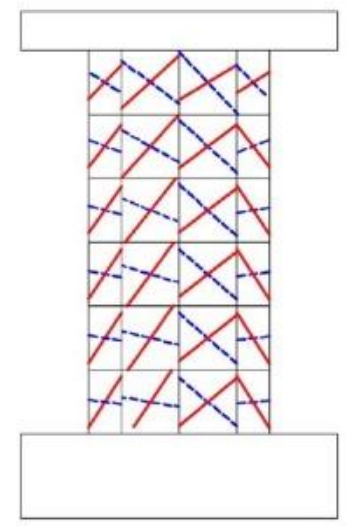

(b)
Figure 10. Comparison of Cracking Patterns of Specimen SW4 [12] (a) Test (b) Model 
The other validation of cracking patterns for rectangular RC walls is presented in Figure 11, which shows the comparison of the cracking patterns for specimen J4 [14]. It can be observed that the model is able to predict the global cracking patterns of the specimen. Nonetheless, the model provides unsymmetrical cracking angle, especially for the right side of the wall web. This may be due to the adoption of FSAM theory, which assumed a fixed angle for subsequent cracks after the first crack formation. Also, the model shows cracks pattern at the middle top of the wall, while there were no notable cracks in the experimental test.

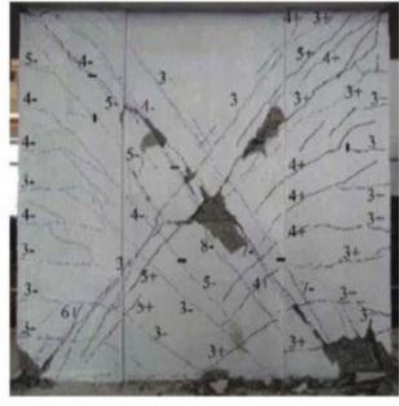

(a)

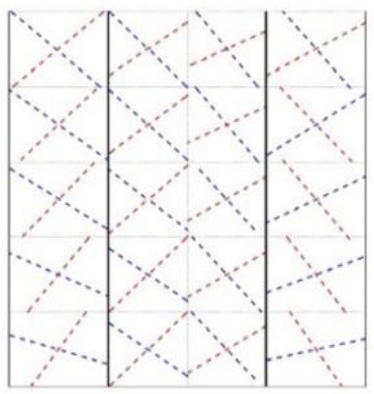

(b)
Figure 11. Comparison of Cracking Patterns of Specimen J4 [14] (a) Test (b) Model

\section{Barbell-shaped RC Wall Specimens}

The first validation of cracking patterns for barbellshaped RC walls is presented in Figure 12, which shows the comparison of cracking patterns for specimen B5 [15]. The cracking angle predicted by the model at the boundary element shows a combination of shear and flexural crack. This may be because the boundary elements were also modeled using the SFI-MVLEM elements. Meanwhile, the cracking pattern at the web area is unsymmetrical, which is probably due to the adoption of FSAM theory.

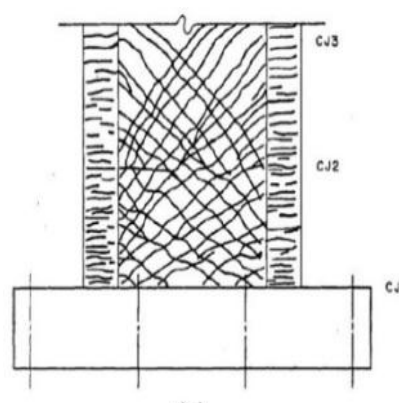

(a)

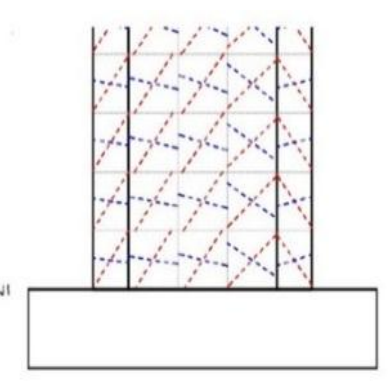

(b)
Figure 12. Comparison of Cracking Patterns of Specimen B5 [15] (a) Test (b) Model

Furthermore, Figure 13 shows the comparison of cracking patterns for specimen W1 [19]. It can be seen that the model is generally able to predict the cracking patterns of the specimen. Some discrepancies present at the boundary elements as well as at the web. For those at the boundary elements, the model predicts a more gradual cracking angle compared to those of experimental test. Moreover, at the web, some cracking angles are unsymmetrical, which differs to the experimental results. This may be due to the adoption of FSAM theory, which assumed a fixed cracking angle after the first crack formed.

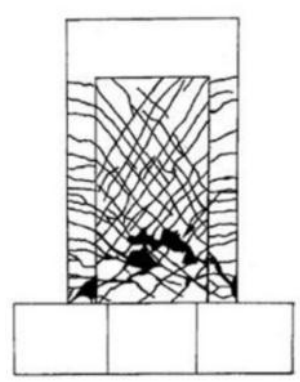

(a)

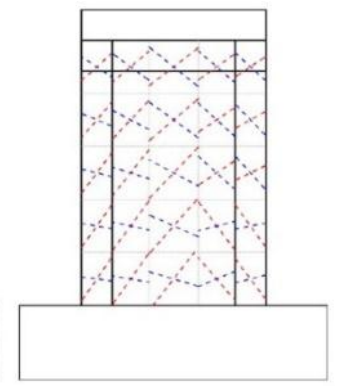

(b)
Figure 13. Comparison of Cracking Patterns of Specimen W1 [19] (a) Test (b) Model

\section{Contribution of Shear and Flexural Deformation}

Contribution of shear and flexural displacement of each $\mathrm{RC}$ wall types, i.e. rectangular, flanged, and barbell-shaped, are represented by specimens J4 [14], F1 [15], and B5 [15], respectively. Firstly, Figure 14 shows the comparison of shear and flexural deformation contribution of specimen $\mathrm{J} 4$ [14]. It can be seen that the model is able to predict the SFI response in the specimen, which is denoted by shear-dominated deformation at later stage of loading. This phenomenon can also be observed in the experimental test results. Moreover, $84.30 \%$ contribution of shear deformation was obtained in the negative direction. Meanwhile, lower contribution of shear deformation in the positive direction was obtained in the model, which was $56.10 \%$. As for the experimental test, the results show that contributions of shear deformation were $62.50 \%$ and $43.30 \%$ for negative and positive directions, respectively. Discrepancies between the results from the model and the experimental results may be attributed to sliding shear deformation which occurred in the experimental test. However, the model could not simulate the sliding shear failure mechanism.

Secondly, Figure 15 shows the comparison of shear and flexural displacement profile for specimen F1 [15]. The results show that the model overestimates the contribution of shear displacement in the positive direction circa $6.46 \%$, while in the negative direction, the model significantly underestimates the contribution of shear displacement by $27.87 \%$. This is due to 
web crushing failure in the experimental test which was not captured by the model. As for the contribution of flexural displacement, it is found that the model underestimates the flexural displacement in both directions. There is negligible discrepancy around $0.12 \%$ in the positive direction. Meanwhile, in the negative direction, the difference between the model and the experimental results is about $13.39 \%$. This also may be due to the local failure on the web of the specimen, which may further reduce the flexural rigidity of the specimen. Nevertheless, considering the shape of the displacement profile, it can be concluded that the model is able to predict general response of the specimen, except the local failure.

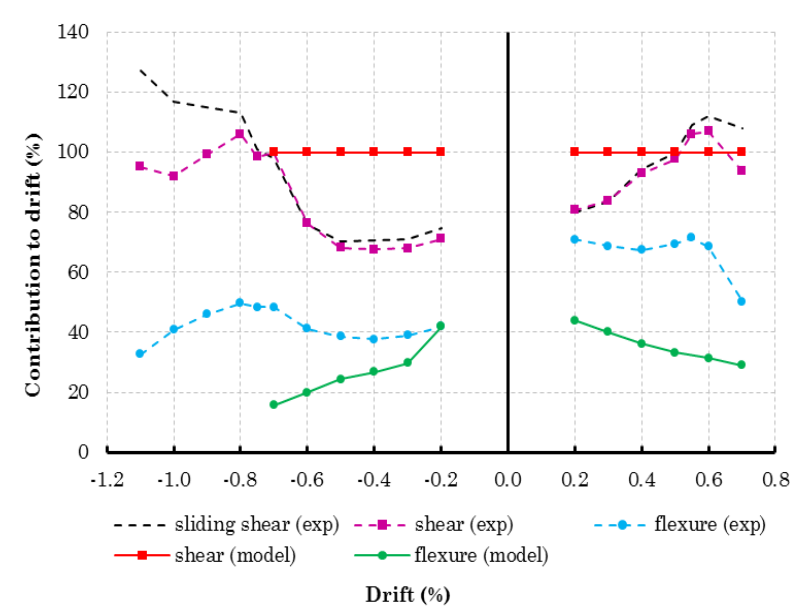

Figure 14. Comparison of Shear and Flexural Drift Contribution of Specimen J4 [14]

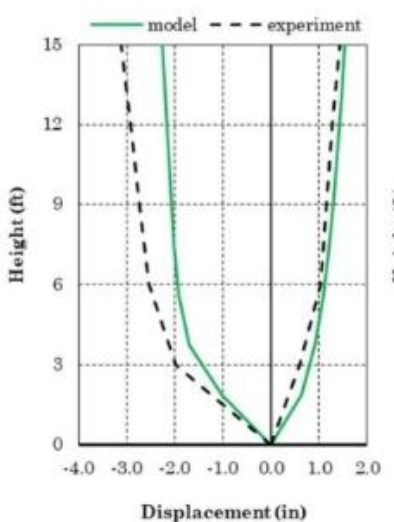

(a)

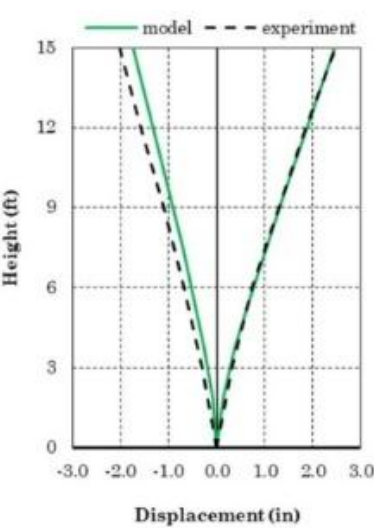

(b)
Figure 15. Comparison of Displacement Profile of Specimen F1 [15] (a) Shear (b) Flexure

Lastly, Figure 16 shows the comparison of shear and flexural displacement profile for specimen B5 [15]. As can be seen, the model predicts higher contribution of shear displacement. The finding reveals that the model overestimates the shear displacement by $1.59 \%$ and $12.74 \%$ in negative and positive directions, respectively. Conversely, the model underestimates the contribution of flexural displacement, which is around $20.89 \%$ and $9.93 \%$ in negative and positive directions, respectively. Identical to the previous specimen, visually the displacement profile predicted by the model is considerably reliable. The notable discrepancies in numerical values are strongly attributed to the inability of the model in simulating the local failure mechanism as occurred in the experimental test.

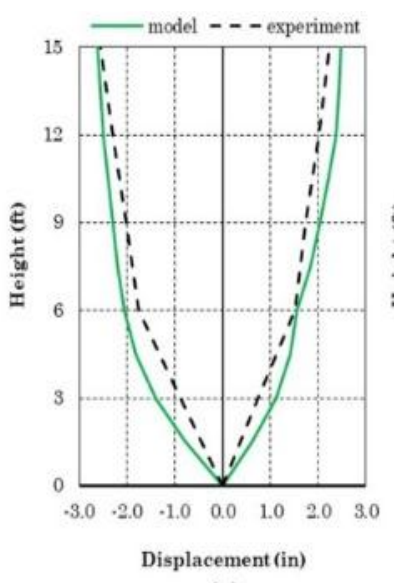

(a)

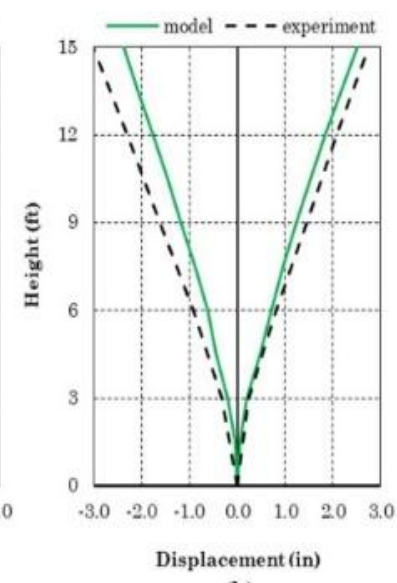

(b)
Figure 16. Comparison of Displacement Profile of Specimen B5 [15] (a) Shear (b) Flexure

\section{Conclusions}

From a number of evaluations to previous experimental test results, it can be concluded that the model, which uses SFI-MVLEM element, is able to predict the response of various types of $\mathrm{RC}$ walls under monotonic and cyclic loading. The results indicate that the model is able to predict the ultimate load of rectangular $\mathrm{RC}$ walls subjected to monotonic loading by introducing less than $10 \%$ difference to the experimental test results. Moreover, for rectangular RC walls under cyclic loading, the model performs incredibly accurate approximation, with only $3 \%$ deviation for ultimate load and displacement in both directions of loading. However, similar to the monotonic loading, the model also introduces higher initial stiffness under cyclic loading. Furthermore, for flanged RC walls, the model can predict the ultimate load accurately with less than $4 \%$ deviation in both directions of loading. The prediction of displacement in the positive direction of loading is also acceptable, which is not larger than $10 \%$ difference. However, moderate estimation of displacement in the negative direction is obtained for specimen J7 [14], which is lower than the experimental results for about $20 \%$. As for barbell-shaped $\mathrm{RC}$ walls, the model can predict the ultimate load and displacement with relative error for about $15 \%$. In addition, the model overestimates the initial stiffness of barbell-shaped RC walls as in the case of rectangular and flanged $\mathrm{RC}$ walls. 
Based on the comparison of cracking patterns, it can be concluded that the model is capable of describing the cracking patterns of the tested specimens. Some discrepancies in terms of unsymmetrical cracking patterns is due to the adoption of FSAM theory, which assumed a fixed angle for subsequent cracking angles after the first crack formation. Another key finding is that the crack angles predicted by the model at the boundary elements for the barbellshaped RC walls show a combination of shear and flexural cracks. This is because the boundary elements were also modeled using SFI-MVLEM element. In terms of contribution of shear deformation to total deformation, the model also provides reliable results. For rectangular $\mathrm{RC}$ wall, i.e. specimen J4 [14], the model predicts $46 \%$ on average for contribution of shear displacement to the total displacement while the experimental results show $48 \%$ on average contribution of shear displacement to total displacement. Thus, the result provided by the model is quite accurate by introducing only $2 \%$ relative difference to the experimental results. Furthermore, for barbell-shaped RC wall specimens, the model results $5 \%$ deviation to the experimental results. Nevertheless, for flanged RC walls, there is moderate difference in the prediction of the contribution of shear deformation between the model and the experimental results, which is about $18 \%$ deviation.

In conclusions, if the specimen was not dominated by local failure, the model is able to accurately predict the hysteretic behavior of $\mathrm{RC}$ walls, including the ultimate load and displacement. The model can also predict the global cracking patterns neglecting the symmetry aspect. In addition, the model is able to simulate the SFI behavior of $\mathrm{RC}$ walls by predicting the contribution of shear and flexural deformations to total wall deformation with reasonable accuracy. Complete analysis results and discussions can be found elsewhere [20,21]. Further research can be conducted to incorporate the effect of local failure mechanism into the model. Moreover, for flanged and barbell shaped RC walls, the SFI-MVLEM element might be combined with nonlinear beam column element to model the wall web and boundary elements, respectively, in order to obtain better prediction of the hysteretic behavior and cracking patterns.

\section{References}

1. Kolozvari, K.I., Analytical Modeling of Cyclic Shear-Flexure Interaction in Reinforced Concrete Structural Walls, Ph.D. Dissertation University of California, Los Angeles, 2013.

2. Jalali, A. and Dashti, F., Nonlinear Behavior of Reinforced Concrete Shear Walls using Macros- copic and Microscopic Models, Engineering Structures, 32(9), 2010, pp. 2959-2968.

3. Orakcal, K., Wallace, J.W., and Conte, J.P., Flexural Modeling of Reinforced Concrete WallsModel Attributes, ACI Structural Journal, 101(5), 2004, pp. 688-698.

4. Massone, L.M., Orakcal, K., and Wallace, J.W., Shear-Flexure Interaction for Structural Walls, ACI Special Publication, 236(7), 2006, pp. 127150.

5. Kolozvari, K., Orakcal, K., and Wallace, J.W., Modeling of Cyclic Shear-Flexure Interaction in Reinforced Concrete Structural Walls. I: Theory, Journal of Structural Engineering, 141(5), 2014, pp. 04014135.

6. Ulugtekin, D., Analytical Modeling of Reinforced Concrete Panel Elements Under Reversed Cyclic Loadings, M.S. Thesis Bogazici University, Istanbul, Turkey, 2010.

7. Orakcal, K., Ulugtekin, D., and Massone, L.M., Constitutive Modeling of Reinforced Concrete Panel Behavior Under Cyclic Loading, Proceedings, $15^{\text {th }}$ World Conference on Earthquake Engineering, Lisbon, Portugal, 2012.

8. Vulcano, A., Bertero, V.V., and Colotti, V., Analytical Modeling of RC Structural Walls, Proceedings of $9^{\text {th }}$ world conference on earthquake engineering, 1988, pp. 41-46.

9. Menegotto, M. and Pinto, E., Method of Analysis for Cyclically Loaded Reinforced Concrete Plane Frames Including Changes in Geometry and Non-Elastic Behavior of Elements under Combined Normal Force and Bending, Proceeding of IABSE Symposium on Resistance and Ultimate Deformability of Structures Acted on by WellDefined Repeated Loads, 1973, pp. 15-22.

10. Filippou, F.C., Popov, E.P., and Bertero, Effects of Bond Deterioration on Hysteretic Behavior of Reinforced Concrete Joints, Earthquake Engineering Research Center, University of California, Berkeley, CA, UCB/EERC-83/19, 1983.

11. Chang, G.A. and Mander, J.B., Seismic Energy Based Fatigue Damage Analysis of Bridge Columns: Part I-Evaluation of Seismic Capacity, State University of New York, Buffalo, NY, NCEER-94-0006, 1994, pp. 222.

12. Pilakoutas, K. and Elnashai, A., Cyclic Behavior of Reinforced Concrete Cantilever Walls, Part I: Experimental Results, ACI Structural Journal, 92(3), 1995, pp. 271-281.

13. Lefas, I.D., Kotsovos, M.D., and Ambraseys, N.N., Behavior of Reinforced Concrete Structural Walls: Strength, Deformation Characteristics, and Failure Mechanism, ACI Structural Journal, 87(1), 1990, pp. 23-31.

14. Teng, S. and Chandra, J., Cyclic Shear Behavior of High-Strength Concrete Structural Walls, ACI Structural Journal, 113(6), 2016, pp. 1335.

15. Corley, W.G., Fiorato, A.E., and Oesterle, R.G., Structural Walls, ACI Special Publication, 72(4), 1981, pp. 77-132. 
16. Burgueno, R., Liu, X., and Hines, E.M., Web Crushing Capacity of High-Strength Concrete Structural Walls: Experimental Study, ACI Structural Journal, 111(1), 2014, pp. 37.

17. Li, B., Pan, Z., and Xiang, W., Experimental Evaluation of Seismic Performance of Squat RC Structural Walls with Limited Ductility Reinforcing Details, Journal of Earthquake Engineering, 19(2), 2015, pp. 313-331.

18. Oesterle, R.G., Fiorato, A.E., Johal, L.S., Carpenter, J.E., Russell, H.G., and Corley, W.G., Earthquake Resistant Structural Walls-Tests of Isolated Walls, PCA Construction Technology Laboratories, Skokie, IL, Rep. to National Science Foundation, 1976, pp. 317.
19. Sittipunt, C., Wood, S.L., Lukkunaprasit, P., and Pattararattanakul, P., Cyclic Behavior of Reinforced Concrete Structural Walls with Diagonal Web Reinforcement, ACI Structural Journal, 98(4), 2001, pp. 554-562.

20. Tiffany and Effendy, K., Permodelan Geser Dinding Geser Beton Untuk Analisis Non-Linier, Undergraduate Thesis Petra Christian University, Surabaya, Indonesia, 2018. (in Bahasa Indonesia).

21. Widjaja, S. and Cornelius, K.G., Permodelan Lentur Dinding Beton Untuk Analisis NonLinier, Undergraduate Thesis Petra Christian University, Surabaya, Indonesia, 2018. (in Bahasa Indonesia). 